\title{
An evaluation of job crafting as an intervention aimed at improving work engagement
}

\begin{tabular}{|c|c|}
\hline \multicolumn{2}{|c|}{$\begin{array}{l}\text { Emmarentia C. Thomas }{ }^{1} \text { (]) } \\
\text { Marieta du Plessis } \\
\text { Kevin G.F. Thomas }\end{array}$} \\
\hline \multicolumn{2}{|c|}{$\begin{array}{l}\text { Affiliations: } \\
\text { 1Department of Industrial } \\
\text { Psychology, Faculty of } \\
\text { Economic and Management } \\
\text { Sciences, University of the } \\
\text { Western Cape, Bellville, } \\
\text { South Africa }\end{array}$} \\
\hline \multicolumn{2}{|c|}{$\begin{array}{l}\text { 2Department of Psychology, } \\
\text { Faculty of Humanities, } \\
\text { University of Cape Town, } \\
\text { Rondebosch, South Africa }\end{array}$} \\
\hline \multicolumn{2}{|c|}{$\begin{array}{l}\text { Corresponding author: } \\
\text { Marieta Plessis, } \\
\text { mduplessis@uwc.ac.za }\end{array}$} \\
\hline \multicolumn{2}{|c|}{$\begin{array}{l}\text { Dates: } \\
\text { Received: } 25 \text { June } 2019 \\
\text { Accepted: } 02 \text { Dec. } 2019 \\
\text { Published: } 23 \text { Mar. } 2020\end{array}$} \\
\hline \multicolumn{2}{|c|}{$\begin{array}{l}\text { How to cite this article: } \\
\text { Thomas, E.C., Du Plessis, M., } \\
\& \text { Thomas, K.G.F. (2020). } \\
\text { An evaluation of job crafting } \\
\text { as an intervention aimed at } \\
\text { improving work engagement. } \\
\text { SA Journal of Industrial } \\
\text { Psychology/SA Tydskrif vir } \\
\text { Bedryfsielkunde, 46(0), } \\
\text { a1703. https://doi.org/ } \\
\text { 10.4102/sajip.v46i0.1703 }\end{array}$} \\
\hline \multicolumn{2}{|c|}{$\begin{array}{l}\text { Copyright: } \\
\text { (c) 2020. The Authors. } \\
\text { Licensee: AOSIS. This } \\
\text { is licensed under the } \\
\text { Creative Commons } \\
\text { Attribution License. }\end{array}$} \\
\hline \multicolumn{2}{|l|}{ Read online: } \\
\hline 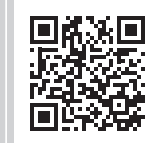 & $\begin{array}{l}\text { Scan this QR } \\
\text { code with your } \\
\text { smart phone or } \\
\text { mobile device } \\
\text { to read online. }\end{array}$ \\
\hline
\end{tabular}

Orientation: In the construction industry, a lack of engagement by employees can have serious and costly health and safety consequences.

Research purpose: The aim of this study was to evaluate whether a job-crafting intervention could improve the work engagement of individuals employed in the construction industry.

Motivation for the study: Because of tight deadlines and stringent requirements, managers in the construction industry are often unable to reduce the demands on, or increase the resources available to, their employees. Hence, if employees are to increase their work engagement, they need to exert personal agency by recrafting their own jobs.

Research approach/design and method: A quasi-experimental research approach was used. One group of employees $(n=33)$ completed the pre- and post-measures and participated in a 1 -day job crafting training session. A comparison group $(n=22)$ only completed the measures, at the same intervals.

Main findings: At the post-intervention measurement point, participants exposed to the intervention showed significantly higher levels of work engagement than those in the comparison group. Across the entire sample, changes in work engagement were correlated with changes in job-crafting behaviours but were not, however, correlated with changes in job demands and resources.

Practical/managerial implications: Job-crafting interventions have the potential to enable employees to proactively improve their work engagement.

Contribution/value-add: The study findings support a relatively rich literature, which suggests that employees who take a proactive role in crafting their job-related tasks and environments tend to take on psychologically fulfilling activities and will be more engaged in their work.

Keywords: work engagement; job crafting; job-crafting intervention; job demands; job resources; quasi-experimental.

\section{Introduction}

\section{Orientation}

The importance of the concept of work engagement and the factors that might affect it have been of keen interest to both academics and practitioners in recent years (e.g. Bakker \& Leiter, 2010). Current literature suggests that increased work engagement is related to important work outcomes such as reduced burnout (Maslach, Schaufeli, \& Leiter, 2001; Ogungbamila, 2018; Steffens, Yang, Jetten, Haslam, \& Lipponen, 2018), increased happiness (Field \& Buitendach, 2011), better organisational commitment (Albdour \& Altarawneh, 2014), decreased turnover intention (De Braine \& Roodt, 2011) and increased job satisfaction (Barkhuizen \& Rothmann, 2006; Mudrak et al., 2018). Furthermore, a highly engaged workforce can increase innovation, productivity and bottom-line performance whilst reducing costs related to hiring and retention in highly competitive talent markets (Bhatnagar, 2007).

In terms of factors that might improve work engagement, industrial or organisational psychological research has, over the past several decades, developed a large literature examining ways in which job characteristics and the work environment affect the degree to which employees engage with their jobs (Schaufeli \& Bakker, 2004). In particular, empirical research has focussed on the influence of job demands and job resources on work engagement, resulting in formalisation of the Job Demands-Resources framework (Bakker \& Demerouti, 2007; Schaufeli \& Bakker, 2004). 
Evidence from research investigating this framework suggests that it is in the employer's best interests that an optimal balance be struck between job demands and job resources so that work engagement is positively affected. To this end, several studies have described and evaluated various job redesign interventions. Most of those studies have focussed on top-down approaches (i.e. approaches that emerge from a manager's [or another change agent's] redesign of the employee's job characteristics and work environment; Bakker \& Leiter, 2010). Recently, however, alternative approaches to job redesign have been described and evaluated in the literature. One specific form of these alternative approaches is job crafting.

The term job crafting refers to proactive employee behaviours that seek to optimise the work environment, frequently by addressing the balance between job demands and job resources (Demerouti, 2014). The key to this definition is the word 'proactive': employees follow their own initiative, and act voluntarily, to affect their daily tasks, the scope of their assignments and the characteristics of their work environment in such a way that the balance of job demands and job resources is shifted towards greater workplace engagement, satisfaction and feelings of efficacy and purpose (Gordon et al., 2018; Lyons, 2008; Tims, Bakker, \& Derks, 2012; Wrzesniewski \& Dutton, 2001).

Because the construction industry is a crucial element of the South African economy, work engagement by employees in that industry is particularly important for improving health, promoting safety and reducing the effects of organisational burnout (Bell, Powell, \& Sykes, 2015; Olusa \& Afolabi, 2017). Furthermore, a lack of such engagement by employees can have serious and costly health and safety consequences (Whiteoak \& Mohamed, 2016). In recent years, several cases of collapsed buildings have made headlines. Although, in most instances, the source of the collapse appeared to be substandard quality of materials, in at least a few instances construction workers have lamented the demanding, highrisk and complex nature of the jobs they performed on the sites of the collapse (De Villiers, 2017; Evans, 2016; Potter, 2016). Furthermore, because construction companies work under tight deadlines and stringent requirements, and hence feel unable to reduce the demands on their employees, the latter need to exert agency in order to recraft their own jobs (Bowen, Edwards, Lingard, \& Cattell, 2014).

\section{Research purpose and objectives}

The primary aim of this research was to evaluate the effectiveness of a job-crafting intervention in improving the levels of employee work engagement. The sample of interest is employees who work in the South African construction industry.

In essence, the study set out to answer this question: 'does a standardised job-crafting intervention have a positive effect on the job demands and job resources, and hence on the work engagement, of employees in the South African construction industry?'

\section{Literature review \\ Job crafting and the Job Demands-Resources model}

Recent research has begun to investigate proactive perspectives on job design. Otherwise stated, scholars and practitioners have begun to consider quite seriously that the individual employee can have an influence on developing or adjusting the boundaries of their tasks and the relational environments of their jobs (Grant \& Ashford, 2008; Grant \& Parker, 2009). Recent studies suggest thatjob crafting might be conceptualised as a key component of the theoretical framework provided by the Job Demands-Resources model (JD-R model).

Within the JD-R model, job demands are defined as those physical, psychological (cognitive and emotional), social or organisational aspects of a job that require sustained effort or skills, and that are therefore associated with certain physiological and/or psychological costs. Hence, most kinds of job demands (e.g. work overload, role conflict, ambiguity and work-life conflict) are energy depleting. Job resources, on the other hand, are defined as those physical, psychological, social or organisational aspects of a job that are functional in achieving work goals, in reducing job demands and in stimulating employee growth, learning and development (Bakker \& Demerouti, 2007). Examples of job resources are job autonomy, a positive workplace climate and co-worker support (Crawford, Lepine, \& Rich, 2010).

The model describes the relationship between job demands and job resources as being a balancing act: too much of the former results in strain, whereas sufficient amounts of the latter result in high motivation. More specifically, the occurrence of job strain results from a depletion of energy caused by a situation where job demands are high, and the employee is not provided with a sufficient amount of the needed job resources (Bakker \& Demerouti, 2007). In contrast, when demands are high and an employee has sufficient resources, employees are motivated and engaged (Brenninkmeijer \& Hekkert-Koning, 2015). In fact, the amount of job resources appears to be the strongest predictor of work engagement, especially in the presence of high job demands (Bakker, 2014; Mudrak et al., 2018; Rothmann, Mostert, \& Strydom, 2006; Vignoli, Muschalla, \& Mariani, 2017).

According to the JD-R model, job crafting can have positive effects (both directly and indirectly) on both job performance and work engagement (Bakker \& Demerouti, 2014; Tims et al., 2012). Job crafting may be conceptualised as the changes employees make to balance their job demands and resources with their personal abilities and needs. Specifically, then, job crafting within that context might be said to consist of three conceptually different dimensions: (1) increasing job resources (e.g. requesting more autonomy and asking for feedback); (2) increasing challenging job demands (e.g. starting new projects) and (3) decreasing hindering job demands, along both cognitive and emotional dimensions (e.g. decreasing the emotional intensity of work or organising work in such a way that concentration is not required for too long a period at once) (Tims \& Bakker, 2010; Tims et al., 2012). 
Several studies demonstrated direct relationships between job crafting, as captured by the three dimensions listed above, and work engagement (see, e.g., Bakker, Oerlemans, \& Ten Brummelhuis, 2013; Tims, Bakker, \& Derks, 2013). For instance, Lee, Shin and Baek (2017) showed, using crosssectional survey-based methodology, in a sample of Korean Master of Business Administration students that (1) jobcrafting behaviours were positively associated with work engagement and (2) job crafting behaviour fully or partially mediated the relationship between certain job resources and work engagement. Similarly, Sakuraya et al. (2017) reported, based on data from a sample of employees from a Japanese manufacturing company $(N=894)$, that (1) increasing structural job resources is associated with higher work engagement and lower psychological distress and (2) increasing both social job resources and challenging job demands is associated with higher work engagement.

\section{Job-crafting interventions}

The intervention used in the current study is modelled upon that described by Van den Heuvel, Demerouti and Peeters (2012). They implemented their job-crafting intervention in a police department. The intervention included training workshops, goal-setting exercises, longitudinal action plans and reflection. Upon evaluation, the authors concluded that the intervention positively affected work engagement (e.g. participants reported experiencing improved relationships with their superiors, with a better two-way flow of communication). Using a similar study design and intervention, but applying them to employees of a health care organisation, Gordon et al. (2018) found that job crafting can improve employee well-being and job performance. Other forms of jobcrafting interventions include the Michigan Job Crafting Exercise (Berg, Dutton, \& Wrzesniewski, 2013) and adaptations thereof using the principles of the JD-R model (Van Wingerden, Derks, \& Bakker, 2017a).

\section{Job-crafting outcomes}

A small group of recently published studies (e.g. Brenninkmeijer \& Hekkert-Koning, 2015; Petrou, Demerouti, Peeters, Schaufeli, \& Hetland, 2012; Tims, Bakker, \& Derks, 2014) suggest that job crafting has positive effects on work engagement (manifested by, for instance, reduced burnout and increased job satisfaction and employee well-being). However, most of those studies used cross-sectional survey methods, and few were conducted in low- and middle-income countries (LAMICs) such as South Africa. In LAMICs, the balance between job resources and job demands might be particularly uneven (Rothmann et al., 2006) as workers have typically not been proactive in determining their job characteristics or shaping their work environment (Rothmann, 2003). Furthermore, these job contexts are quite different from those in high-income countries (HICs), such as the Netherlands and Australia, where much of the job-crafting literature originates (Wrzesniewski \& Dutton, 2001). Nonetheless, one of the few South African job-crafting studies found, using a sample of high school teachers from the Gauteng province, that those who were allowed proactive opportunities to fashion their working practices (i.e. those whose work contexts were characterised by high levels of structural resources and challenging job demands) experienced increased work engagement (Peral \& Geldenhuys, 2016). Hence, there is evidence suggesting that the positive effects of job-crafting interventions might persist across different cultures, socio-economic strata and work contexts.

The proposed study seeks to add to the existing job-crafting literature by describing and evaluating the implementation of an employee-initiated job redesign intervention in an organisation in the South African construction industry. The aim of the study is therefore to test the following major hypothesis:

H1: There is a positive relationship between job crafting and work engagement amongst employees working in a South African construction company. Specifically, relative to participants in a non-intervention comparison group, participants who receive a job crafting intervention will, because of their changed experiences relating to job resources (higher) and job demands (lower), demonstrate higher levels of work engagement at postintervention measurement than at pre-intervention measurement.

\section{Research design Research approach}

The study used a quantitative, quasi-experimental research design. All participants were recruited via convenience sampling. Individuals from two different construction sites $(n=30)$ were assigned to the Control group and individuals from two other construction sites $(n=34)$ to the Intervention group. This aspect of the design meant that the effect of contamination was limited (i.e. the design limited the risk of the experience of participants in one condition affecting that of participants in the other condition). The job-crafting intervention consisted of a training workshop, a personal crafting plan and reflective exercises, all following those described by Van den Heuvel et al. (2012). Outcome measures (all based on self-report questionnaires) were taken before and after the intervention was implemented.

\section{Research participants}

The population for this study comprised employees of the Western Cape division of a national construction company. The rationale for sampling from this population is that this company is one of the five biggest South African construction corporations.

Sixty-four individuals constituted the initial sample. Of these, 33 (five women, 28 men) were assigned to the Intervention group and 31 (five women, 26 men) were assigned to the Control group. Across the course of the study, nine individuals in the Control group (one woman, eight men) dropped out - the woman because she went on maternity leave, three men because they resigned from the company and four other men because they went on annual leave. Another man in the Control group did not complete all of the questions on the post-intervention measures. 
Hence, the final sample for data analysis was constituted thus: Intervention group $=33$ (five women, 28 men) and Control group $=22$ (four women, 18 men). The general job classification of each individual was either administrative (e.g. health and safety clerk), managerial (e.g. contracts manager), operational (e.g. foreman) or technical (e.g. engineer).

\section{Measuring instruments}

The instruments comprised a biographical questionnaire and three standardised measurement scales: (1) the Utrecht Work Engagement Scale (UWES-17), (2) the Job Crafting Scale (JCS) and (3) the Jobs Demands-Resources Scale (JDRS).

On the UWES-17, items are scored on a 7-point Likert-type scale, with response options ranging from 0 (never) to 6 (always). Schaufeli and Bakker (2004) established that the scale measures three underlying dimensions of work engagement: vigour is measured using six items (e.g. 'At my work, I feel bursting with energy', with Cronbach's alpha $[\alpha]$ $=0.75-0.82$ ); dedication is measured with five items (e.g. 'My job inspires me', with $\alpha=0.88-0.90)$ and absorption with six items (e.g. 'Time flies when I am working', with $\alpha=0.70$ 0.75). Internal consistency and reliability for the three subscales ranges between $\alpha=0.68$ and $\alpha=0.91$ (Coetzee \& Rothmann, 2005; Field \& Buitendach, 2011).

The JCS (Tims et al., 2012) consists of 21 items, each scored on a five-point Likert-type scale, with response options ranging from 1 (never) to 5 (very often). The developers report that the scale measures four independent factors, each with a reliability coefficient considered to be at least adequate. The first factor, Increasing social job resources, is measured using five items (e.g. 'I ask others for feedback on my job performance'), with $\alpha=0.78$. The second factor, increasing structural job resources, is also measured using five items (e.g. 'I make sure that I use my capacities to the fullest'), with $\alpha=0.71$. The third factor, increasing challenging job demands, is also measured using five items (e.g. 'When there is not much to do at work, I see it as an opportunity to start new projects'), with $\alpha=0.69$. The fourth factor, decreasing hindering job demands, is measured using six items (e.g. 'I make sure that my work is mentally less intense'), with $\alpha=0.73$.

The JDRS (Rothmann et al., 2006) measures five independent factors, each with a reliability coefficient considered to be at least adequate. The first factor, growth opportunities $(\alpha=0.86)$, is derived from items that ask about having enough variety, opportunities to learn and independence in the job. The second factor, organisational support ( $\alpha=0.92)$, is derived from items that ask about the relationship with supervisors and colleagues, flow of information, communication, role clarity and participation in decision-making. The third factor, advancement ( $\alpha=0.83$ ), is derived from items asking about remuneration, career possibilities and training opportunities. The fourth factor, overload ( $\alpha=0.76$ ), is derived from items asking about pace and amount of work, mental load and emotional load. The fifth factor, job insecurity $(\alpha=0.89)$, is derived from items asking about uncertainty regarding work future.

\section{Research procedure and ethical considerations}

All procedures took place at the participant's site of work. With the permission of their line managers, participants completed questionnaires and other study-related activities during work hours. The pre-intervention phase involved the participants reading and signing an informed consent document, and then completing the biographical questionnaires, the UWES-17, the JCS and the JDRS. The post-intervention phase required the participants to complete the UWES-17, the JCS and the JDRS again.

To ensure participant anonymity and the confidentiality of their data, a unique code was assigned to each participant. This code was used on all pre- and post-intervention questionnaires. The key to the code is held in a passwordprotected file and only the researchers have access to it.

Ethical clearance for the study was obtained from the Human and Social Sciences Ethics Committee at the University of the Western Cape (reference number: 15/6/47).

\section{Procedures specific to the intervention group}

For participants assigned to the Intervention group, the jobcrafting intervention began 2-4 weeks after completion of the pre-intervention measurements, with variation dependent on work schedules at each site. The intervention consisted of a training workshop, a personal crafting plan and a reflection exercise, all of which took place over a period of 4 weeks (see Table 1 ).

Each training workshop was presented to a group of 6-8 participants by the first author. The training workshop took the format of a presentation and subsequent focus-group discussions and exercises. The presentation began with a discussion on work engagement and what it means to be engaged at work. Thereafter, the JD-R model was explained before launching into descriptions of: (1) what job crafting means, (2) success stories of past job-crafting behaviours and (3) case study examples. At the conclusion of the presentation, participants were divided into pairs. They were instructed to write down and discuss what their job demands were, what job resources they had available to them, how they could decrease the former and increase the latter, and then how they could use increased resources to further reduce demands. Each pair then presented to the larger group what they had written down, and the researcher invited discussions around the identified issues and challenges. Subsequently, participants were asked to discuss which things they could change in their work to increase social job resources, structural job resources and challenging job demands.

TABLE 1: Overview of the job-crafting intervention timeline.

\begin{tabular}{lll}
\hline Phase & Intervention & Week \\
\hline Pre-intervention & Pre-measurement & Week 1 \\
Intervention & Training workshop & Week 2 \\
& Personal crafting plan & Week 2 \\
& Reflection exercise & Week 5 \\
Post-intervention & Post measurement & Week 6 \\
\hline
\end{tabular}


Overall, the aim of this goal-setting exercise was to stimulate participants to (1) proactively optimise their own job demands and resources, (2) gain an understanding of how job crafting can be applied to any job and (3) reflect on their current work performance.

The second part of the training workshop consisted of an individual exercise that resulted in a personal crafting plan. This exercise involved each participant describing the jobcrafting goals and actions they would undertake, based on the previous exercise and discussions. Participants were instructed to set two goals for increasing job resources and one goal for decreasing job demands. For each goal, the participant had to identify pathways to achievement and possible obstacles to completion. Before the workshop concluded, participants were reminded that they should aim to set one goal and to achieve that goal during each of the weeks following the training.

The reflection exercise took place 3 weeks after the training workshop. This exercise took place within the context of focus-group sessions, each featuring the same 6-8 participants as were grouped together for the training workshop. During these group discussions, the facilitator guided reflection on the challenges the participants had experienced in attempting to achieve their job-crafting goals, what had worked well during the intervention phase and whether they had succeeded in accomplishing their goals. The participants were also encouraged to discuss what they would need in the future to maintain the fit between their personal competencies, their preferences and their job. Ultimately, the aim of these reflection discussions, and the intervention overall, was to teach participants what they could do to change elements of their jobs and their relationships with others in order to increase their job resources at work.

The post-intervention phase took place shortly after completion of the intervention phase (i.e. within a week of the reflection exercise).

\section{Statistical analysis}

Analysis of the collected data proceeded across six broad steps. Firstly, after collecting the questionnaires from the participants' worksites, all raw data were entered into a Microsoft Excel spreadsheet. Secondly, outcome variables of interest (i.e. scores on each of the UWES-17, JCS and JDRS subscales) were derived by adding together the appropriate item scores (Rothmann et al., 2006; Schaufeli \& Bakker, 2004; Tims et al., 2012). Thirdly, a complete set of descriptive statistics was generated for: (1) each key sample biographic characteristic (age, gender and the highest level of education); (2) each key sample employment characteristic (length of service at the construction company, length of time in the current position, current work status (full-time versus contract) and current job classification (administrative, managerial, operational, technical or other); and (3) each outcome variable. These descriptive statistics allowed examination of the data distributions and the assumptions underlying subsequent inferential analyses; (4) a series of chi- square tests of independence assessed between-group differences with regard to each key biographic and employment characteristic; (5) a series of 2 (Time: pre-intervention, postintervention) $\times 2$ (Group: Intervention, Control) repeatedmeasures analysis of variances (ANOVAs) and follow-up independent-samples $t$-tests evaluated the changes in UWES-17, JCS and JDRS subscale scores from pre- to post-intervention. Sixthly, a series of bivariate correlational analyses (using Pearson's $r$ correlation coefficient) assessed the magnitude of relationships between UWES-17, JCS and JRDS from pre- to post-intervention change scores.

All analyses were completed using SPSS (version 24), with the threshold for statistical significance $(\alpha)$ set at 0.05 , unless noted otherwise.

\section{Results \\ Sample characteristics}

Table 2 presents information describing the basic biographical characteristics of the sample and the results of the relevant between-group comparisons. Although the analyses detected no significant between-group differences with regard to sex distribution across the groups, significant age- and educationrelated differences were detected. Specifically, participants in the Intervention group were, on average, significantly younger and highly educated than those in the Control group.

Analyses detected no significant between-group differences with regard to length of service with the employer, tenure, employment status (i.e. permanent or contract) and general distribution of job types.

\section{Major analyses I: Change from pre- to post-intervention}

Table 3 presents relevant descriptive statistics, split by group, for the study's three major measures. These were the data used in analyses, described subsequently and, with results depicted in Table 4, testing the hypotheses that scores on UWES-17, JCS and JDRS subscales would:

- statistically significantly change, in the direction of more positive work engagement, more job crafting, more job resources and challenging job demands, and fewer hindering job demands, from pre- to post-intervention in the Intervention group but not in the Control group

- be statistically significantly higher in terms of work engagement, job crafting, job resources and challenging job demands, and statistically significantly lower in terms of hindering job demands, at post-intervention in the Intervention group than in the Control group.

Regarding UWES-17 outcomes, analyses detected a significant Time $\times$ Group interaction effect on all three subscale scores (see Table 4). In each case, scores for Intervention-group participants increased from pre- to postintervention, whereas scores for Control-group participants decreased. A series of independent-samples $t$-tests indicated 
that post-intervention Vigour, Dedication and Absorption scores for Intervention-group participants were, on average, significantly higher than those for Control-group participants, $t(32.07)=3.11, p=0.002, t(29.63)=2.49, p=0.009$ and $t(31.68)$ $=3.02, p=0.002$, respectively (here, as in similar $t$-tests reported below, all reported $p$-values are one-tailed).

Regarding JCS outcomes, analyses detected a significant Time $\times$ Group interaction effect on all four subscale scores (see Table 4). In each case, scores for Intervention-group participants increased from pre- to post-intervention, whereas scores for Control-group participants decreased.

TABLE 2: Sample socio-demographic characteristics $(N=55)$.

\begin{tabular}{|c|c|c|c|c|c|}
\hline \multirow[t]{2}{*}{ Variable } & \multicolumn{2}{|c|}{ Group } & \multirow[t]{2}{*}{$\chi^{2}$} & \multirow[t]{2}{*}{$p$} & \multirow[t]{2}{*}{ ESE } \\
\hline & $\begin{array}{l}\text { Control } \\
(n=22)\end{array}$ & $\begin{array}{c}\text { Intervention } \\
(n=33)\end{array}$ & & & \\
\hline Age (years) $\dagger$ & - & - & 5.24 & $0.02 *$ & 0.31 \\
\hline$<20$ & 0 & 1 & - & - & - \\
\hline $20-29$ & 4 & 15 & - & - & - \\
\hline $30-39$ & 9 & 9 & - & - & - \\
\hline $40-49$ & 5 & 6 & - & - & - \\
\hline $50-59$ & 2 & 1 & - & - & - \\
\hline $60-69$ & 2 & 1 & - & - & - \\
\hline Gender & - & - & 0.08 & 0.77 & 0.04 \\
\hline Male & 18 & 28 & - & - & - \\
\hline Female & 4 & 5 & - & - & - \\
\hline Highest level of education $\uparrow$ & - & - & 6.54 & $0.01 *$ & 0.38 \\
\hline$\leq$ Grade 11 & 4 & 1 & - & - & - \\
\hline Grade 12 & 9 & 8 & - & - & - \\
\hline Post-matric diploma & 3 & 7 & - & - & - \\
\hline Bachelor's degree & 0 & 8 & - & - & - \\
\hline Postgraduate degree & 2 & 3 & - & - & - \\
\hline Length of service & - & - & 2.30 & 0.13 & 0.20 \\
\hline$<1$ years & 5 & 7 & - & - & - \\
\hline $1-2$ years & 5 & 10 & - & - & - \\
\hline $3-5$ years & 4 & 10 & - & - & - \\
\hline $6-10$ years & 3 & 2 & - & - & - \\
\hline $11-15$ years & 2 & 2 & - & - & - \\
\hline $16-20$ years & 1 & 0 & - & - & - \\
\hline $21-25$ years & 1 & 0 & - & - & - \\
\hline $26-30$ years & 0 & 1 & - & - & - \\
\hline$>31$ years & 1 & 1 & - & - & - \\
\hline Tenure in current position & - & - & 1.93 & 0.17 & 0.19 \\
\hline$<1$ years & 6 & 8 & - & - & - \\
\hline $1-2$ years & 6 & 16 & - & - & - \\
\hline $3-5$ years & 5 & 4 & - & - & - \\
\hline $6-10$ years & 4 & 3 & - & - & - \\
\hline $11-15$ years & 0 & 1 & - & - & - \\
\hline $16-20$ years & 1 & 1 & - & - & - \\
\hline Employment status & - & - & 0.99 & 0.32 & 0.15 \\
\hline Full-time & 15 & 25 & - & - & - \\
\hline Contract & 2 & 1 & - & - & - \\
\hline Job type & - & - & 1.89 & 0.76 & 0.22 \\
\hline Administrative & 4 & 7 & - & - & - \\
\hline Managerial & 6 & 9 & - & - & - \\
\hline Operational & 7 & 13 & - & - & - \\
\hline Technical & 3 & 3 & - & - & - \\
\hline Other & 2 & 1 & - & - & - \\
\hline
\end{tabular}

Note: Data provided are raw counts.

$\chi^{2}$, chi-square; ESE, effect size estimate (in this case, Cramer's V).

$\dagger$, Statistical analyses are presented for those younger than 30 years versus those 30 years or older; $\uparrow$, Statistical analyses are presented for those who completed 12 years (matric) or les of education versus those with post-matric qualifications. Note that four data points were missing for the Control group and six for the Intervention group.

$*, p<0.05$. All $p$-values are two-tailed.
A series of independent-samples $t$-tests indicated that postintervention scores for Intervention-group participants on the Increasing Social Job Resources and Increasing Structural Job Resources subscales were, on average, significantly higher than those for Control-group participants, $t(53)=3.20$, $p=0.001$ and $t(53)=2.25, p=0.014$, respectively. For the other two JCS subscales (Increasing Challenging Job Demands and Decreasing Hindering Job Demands), scores for Interventiongroup participants trended strongly towards being significantly higher than those for Control-group participants, $t(26.64)=1.71, p=0.05$ and $t(53)=1.57, p=0.06$, respectively.

Furthermore, regarding JCS outcomes, the significant main effect of Group on Increasing Social Job Resources reflects the observation that, on average across the two measurement occasions, scores of Intervention-group participants were higher than those of Control-group participants. Similarly, the significant main effect of Time on Increasing Challenging Job Demands reflects the observation that, across groups and on average, postintervention scores were higher than pre-intervention scores. Neither of these findings challenges the a priori predictions; indeed, both of them are driven by the fact that post-intervention scores of Intervention-group participants were so much higher than all other scores in the set (see Table 3).

Regarding the JDRS resources component, analyses detected a significant Time $\times$ Group interaction effect on Growth Opportunities and Organisational Support (but not Advancement) subscale scores (see Table 4). In each case, scores for Intervention-group participants increased from

TABLE 3: Descriptive statistics for the study's three major measures $(N=55)$.

\begin{tabular}{|c|c|c|c|c|c|c|c|c|}
\hline \multirow[t]{4}{*}{ Scale or subscale } & \multicolumn{8}{|c|}{ Group } \\
\hline & \multicolumn{4}{|c|}{ Control $(n=22)$} & \multicolumn{4}{|c|}{ Intervention $(n=33)$} \\
\hline & \multicolumn{2}{|c|}{ Pre } & \multicolumn{2}{|c|}{ Post } & \multicolumn{2}{|c|}{ Pre } & \multicolumn{2}{|c|}{ Post } \\
\hline & $n$ & $\%$ & $n$ & $\%$ & $n$ & $\%$ & $n$ & $\%$ \\
\hline \multicolumn{9}{|l|}{ UWES-17 } \\
\hline Vigour & 4.87 & 0.90 & 4.24 & 1.00 & 4.56 & 0.91 & 4.98 & 0.63 \\
\hline Dedication & 5.19 & 0.79 & 4.67 & 0.90 & 5.04 & 0.69 & 5.19 & 0.50 \\
\hline Absorption & 5.03 & 0.86 & 4.44 & 0.99 & 4.78 & 0.88 & 5.19 & 0.47 \\
\hline \multicolumn{9}{|l|}{ JCS } \\
\hline $\begin{array}{l}\text { Increasing Social Job } \\
\text { Resources }\end{array}$ & 17.18 & 3.92 & 16.73 & 3.49 & 17.39 & 3.18 & 19.67 & 3.24 \\
\hline $\begin{array}{l}\text { Increasing structural job } \\
\text { resources }\end{array}$ & 22.27 & 1.55 & 21.14 & 2.27 & 20.97 & 2.17 & 22.42 & 1.94 \\
\hline $\begin{array}{l}\text { Increasing challenging job } \\
\text { demands }\end{array}$ & 17.68 & 3.43 & 17.45 & 3.60 & 17.12 & 2.88 & 19.73 & 2.25 \\
\hline $\begin{array}{l}\text { Decreasing hindering job } \\
\text { demands }\end{array}$ & 22.00 & 8.19 & 19.50 & 3.79 & 19.36 & 3.98 & 21.45 & 4.91 \\
\hline \multicolumn{9}{|l|}{ JDRS } \\
\hline Growth opportunities & 61.77 & 7.93 & 54.86 & 7.74 & 56.36 & 6.58 & 60.58 & 6.77 \\
\hline Organisational support & 23.09 & 3.07 & 20.64 & 4.36 & 21.67 & 3.20 & 22.88 & 3.47 \\
\hline Advancement & 23.86 & 5.11 & 21.50 & 4.39 & 23.09 & 4.04 & 23.21 & 5.07 \\
\hline Overload & 24.55 & 2.60 & 25.14 & 3.12 & 23.73 & 2.07 & 24.67 & 2.94 \\
\hline Job insecurity & 8.59 & 2.75 & 8.45 & 2.56 & 8.36 & 2.42 & 8.09 & 2.64 \\
\hline
\end{tabular}

Note: Data are means, with standard deviations in brackets.

UWES-17, Utrecht Work Engagement Scale 17-item version; JCS, Job Crafting Scale; JDRS, Job Demands-Resources Scale. 
TABLE 4: Repeated-measures analysis of variance: Change in work engagement, job crafting and job resources-demands scores from pre- to post-intervention in the two groups $(N=55)$.

\begin{tabular}{|c|c|c|c|c|}
\hline Measure & Subscale or effect tested & $F$ & $p$ & ESE \\
\hline \multirow[t]{12}{*}{ UWES-17 } & Vigour & - & - & - \\
\hline & Time & 0.53 & 0.47 & 0.01 \\
\hline & Group & 1.25 & 0.27 & 0.02 \\
\hline & Time $\times$ group & 14.86 & $<0.001 * * *$ & 0.22 \\
\hline & Dedication & - & - & - \\
\hline & Time & 1.79 & 0.19 & 0.03 \\
\hline & Group & 1.51 & 0.22 & 0.03 \\
\hline & Time $\times$ group & 8.06 & $0.006 * *$ & 0.13 \\
\hline & Absorption & - & - & - \\
\hline & Time & 0.97 & 0.33 & 0.02 \\
\hline & Group & 1.80 & 0.19 & 0.03 \\
\hline & Time $\times$ group & 10.79 & $0.002 * *$ & 0.17 \\
\hline \multirow[t]{16}{*}{ JCS } & Increasing Social Job Resources & - & - & - \\
\hline & Time & 2.79 & 0.10 & 0.05 \\
\hline & Group & 5.11 & $0.03 *$ & 0.09 \\
\hline & Time $\times$ group & 4.51 & $0.04 *$ & 0.08 \\
\hline & Increasing structural job resources & - & - & - \\
\hline & Time & 0.34 & 0.56 & 0.01 \\
\hline & Group & 0.05 & 0.83 & 0.001 \\
\hline & Time $\times$ group & 11.73 & $0.001 * *$ & 0.18 \\
\hline & $\begin{array}{l}\text { Increasing challenging job } \\
\text { demands }\end{array}$ & - & - & - \\
\hline & Time & 7.23 & $0.01 *$ & 0.12 \\
\hline & Group & 0.61 & 0.44 & 0.01 \\
\hline & Time $\times$ group & 6.36 & $0.02 *$ & 0.11 \\
\hline & Decreasing hindering job demands & - & - & - \\
\hline & Time & 0.01 & 0.94 & $<0.001$ \\
\hline & Group & 0.06 & 0.81 & 0.001 \\
\hline & Time $\times$ group & 6.26 & $0.02 *$ & 0.11 \\
\hline \multirow[t]{20}{*}{ JDRS } & Growth opportunities & - & - & - \\
\hline & Time & 2.22 & 0.14 & 0.04 \\
\hline & Group & 0.04 & 0.85 & 0.001 \\
\hline & Time $\times$ group & 38.74 & $<0.001 * * *$ & 0.42 \\
\hline & Organisational support & - & - & - \\
\hline & Time & 1.21 & 0.28 & 0.02 \\
\hline & Group & 0.23 & 0.63 & 0.004 \\
\hline & Time $\times$ group & 8.73 & $0.005^{* *}$ & 0.14 \\
\hline & Advancement & - & - & - \\
\hline & Time & 1.45 & 0.24 & 0.03 \\
\hline & Group & 0.17 & 0.68 & 0.003 \\
\hline & Time $\times$ group & 1.54 & 0.22 & 0.03 \\
\hline & Overload & - & - & - \\
\hline & Time & 3.82 & 0.06 & 0.07 \\
\hline & Group & 0.95 & 0.33 & 0.02 \\
\hline & Time $\times$ group & 0.03 & 0.86 & 0.001 \\
\hline & Job insecurity & - & - & - \\
\hline & Time & 0.06 & 0.81 & 0.001 \\
\hline & Group & 0.33 & 0.57 & 0.01 \\
\hline & Time $\times$ group & 0.17 & 0.68 & 0.003 \\
\hline
\end{tabular}

UWES-17, Utrecht Work Engagement Scale, 17-item version; JCS, Job Crafting Scale; JDRS, Job Demands-Resources Scale; ESE, effect size estimate (in this case, partial eta squared, $\eta_{p}{ }^{2}$ ), $F, F$ statistic.

Note: Degrees of freedom were $(1,53)$ for each test

$*, p<0.05 ; * *, p<0.01 ; * * *, p<0.001$. All $p$-values are two-tailed.

pre- to post-intervention, whereas scores for Control-group participants decreased. A series of independent-samples $t$-tests indicated that post-intervention scores for Interventiongroup participants on the Growth Opportunities and Organisation Support subscales were, on average, significantly higher than those for Control-group participants, $t(53)=2.96, p=0.003$ and $t(53)=2.04, p=0.02$, respectively.
Regarding the JDRS demands component, analyses detected no significant main or interaction effects on either Overload or Job Insecurity. Independent-samples $t$-tests detected no significant between-group differences with regard to postintervention Overload or Job Insecurity scores, $t(53)=-0.57$, $p=0.29$ and $t(53)=-0.69, p=0.25$, respectively.

\section{Major analyses II: Associations between changes in outcome variables}

The data analysed here were the change scores (postintervention minus pre-intervention) for each of the UWES17, JCS and JDRS subscale scores (presented in Tables 5 and 6). Analyses tested the hypothesis that there would be statistically significant positive correlations in the Intervention group, but not in the Control group, between change scores across the variables.

Within the Intervention group, analyses detected only the following statistically significant positive associations:

- UWES-17 Absorption and JCS Increasing Social Job Resources, $r=0.40, p=0.02$

- UWES-17 Absorption and JCS Increasing Structural Job Resources, $r=0.38, p=0.03$

- UWES-17 Absorption and JCS Increasing Challenging Job Demands, $r=0.36, p=0.04$

- UWES-17 Vigour and JCS Increasing Challenging Job Demands, $r=0.46, p=0.007$

- JCS Increasing Social Job Resources and JDRS Growth Opportunities, $r=0.34, p=0.01$

- JCS Increasing Challenging Job Demands and JDRS Organisational Support, $r=0.49, p=0.004$.

Within the Control group, analyses detected only the following statistically significant associations:

- UWES-17 Dedication and JCS Increasing Structural Job Resources, $r=0.50, p=0.02$

- UWES-17 Absorption and JCS Increasing Structural Job Resources, $r=0.57, p=0.005$

- JCS Increasing Structural Job Resources and JDRS Advancement, $r=-0.56, p=0.007$.

\section{Discussion Outline of the results}

The overall objective of this study was to evaluate the effectiveness of a job-crafting intervention in improving the levels of employee work engagement.

Analyses indicated that post-intervention work engagement (as indexed by UWES-17 Vigour, Dedication and Absorption scores) of Intervention-group participants was significantly greater than that of Control-group participants. This result is consistent with those of several previous studies describing a strong positive relationship between increased employee involvement in job-crafting activities and improved work engagement (e.g. Bakker, Tims, \& Derks, 2012; Nell, 2015; 
TABLE 5: Correlation matrix: Job Crafting Scale subscales, Job Demands-Resources Scale subscales and Utrecht Work Engagement Scale-17 subscales. Variable

\begin{tabular}{|c|c|c|c|c|c|c|c|c|c|c|c|c|c|c|c|c|c|}
\hline & & & & & & & & & & & & & & & & & \\
\hline & & \multicolumn{4}{|c|}{$\begin{array}{c}\text { Increasing } \\
\text { social job resources }\end{array}$} & \multicolumn{4}{|c|}{$\begin{array}{c}\text { Increasing } \\
\text { structural job resources } \\
\end{array}$} & \multicolumn{4}{|c|}{$\begin{array}{c}\text { Increasing } \\
\text { challenging job demands }\end{array}$} & \multicolumn{4}{|c|}{$\begin{array}{c}\text { Decreasing } \\
\text { hindering job demands }\end{array}$} \\
\hline & & \multicolumn{2}{|c|}{ Control } & \multicolumn{2}{|c|}{ Intervention } & \multicolumn{2}{|c|}{ Control } & \multicolumn{2}{|c|}{ Intervention } & \multicolumn{2}{|c|}{ Control } & \multicolumn{2}{|c|}{ Intervention } & \multicolumn{2}{|c|}{ Control } & \multicolumn{2}{|c|}{ Intervention } \\
\hline & & $r$ & $p$-value & $r$ & $p$-value & $r$ & $p$-value & $r$ & $p$-value & $r$ & $p$-value & $r$ & $p$-value & $r$ & $p$-value & $r$ & $p$-value \\
\hline \multirow[t]{5}{*}{ JDRS } & Growth opportunities & 0.09 & 0.69 & 0.43 & $0.01 *$ & -0.07 & 0.78 & 0.18 & 0.31 & -0.20 & 0.38 & 0.25 & 0.15 & -0.02 & 0.95 & 0.06 & 0.76 \\
\hline & Organisational support & 0.10 & 0.67 & 0.22 & 0.22 & -0.05 & 0.82 & 0.20 & 0.26 & -0.15 & 0.51 & 0.49 & $0.004 * *$ & 0.06 & 0.80 & -0.24 & 0.18 \\
\hline & Advancement & -0.023 & 0.92 & -0.22 & 0.22 & -0.56 & $0.007 * *$ & -0.06 & 0.75 & 0.01 & 0.98 & 0.14 & 0.44 & 0.39 & 0.08 & 0.16 & 0.37 \\
\hline & Overload & -0.08 & 0.71 & -0.23 & 0.19 & -0.32 & 15 & 0.23 & 0.20 & 0.01 & 0.96 & 0.08 & 0.67 & -0.03 & 0.89 & -0.07 & 0.72 \\
\hline & Job insecurity & -0.25 & 0.27 & 0.06 & 0.74 & -0.23 & 0.31 & -0.17 & 0.36 & 0.06 & 0.81 & 0.04 & 0.82 & 0.26 & 0.24 & 0.29 & 1.00 \\
\hline \multirow[t]{3}{*}{ UWES-17 } & Vigour & 0.04 & 0.85 & 0.31 & 0.08 & 0.41 & 0.06 & 0.20 & 0.27 & 0.06 & 0.80 & $0.46 * *$ & 0.007 & -0.13 & 0.56 & -0.005 & 0.98 \\
\hline & Dedication & 0.09 & 0.69 & 0.23 & 0.20 & 0.50 & $0.02 *$ & 0.20 & 0.26 & 0.26 & 0.24 & 0.34 & 0.06 & -0.25 & 0.26 & 0.01 & 0.95 \\
\hline & Absorption & 0.23 & 0.31 & 0.40 & $0.02 *$ & 0.57 & $0.005^{* *}$ & 0.38 & $0.03 *$ & 0.26 & 0.25 & 0.36 & $0.04 *$ & -0.03 & 0.88 & 0.17 & 0.36 \\
\hline
\end{tabular}

Note: Statistically significant $p$-values are highlighted in boldface font.

JCS, Job-Crafting Scale; JDRS, Job Demands-Resources Scale; UWES-17, Utrecht Work Engagement Scale, 17-item version; $r$, Pearson's $r$ correlation coefficients.

$*, p<0.05 ; * *, p<0.01$.

TABLE 6: Correlation matrix: Job Demands-Resources Scale subscales and Utrecht Work Engagement Scale-17 subscales.

\begin{tabular}{|c|c|c|c|c|c|c|c|c|c|c|c|c|c|c|c|c|c|c|c|c|}
\hline \multirow[t]{4}{*}{ Variable } & \multicolumn{20}{|c|}{ JDRS subscale } \\
\hline & \multicolumn{4}{|c|}{ Growth opportunities } & \multicolumn{4}{|c|}{ Organisational support } & \multicolumn{4}{|c|}{ Advancement } & \multicolumn{4}{|c|}{ Overload } & \multicolumn{4}{|c|}{ Job insecurity } \\
\hline & \multicolumn{2}{|c|}{ Control } & \multicolumn{2}{|c|}{ Intervention } & \multicolumn{2}{|c|}{ Control } & \multicolumn{2}{|c|}{ Intervention } & \multicolumn{2}{|c|}{ Control } & \multicolumn{2}{|c|}{ Intervention } & \multicolumn{2}{|c|}{ Control } & \multicolumn{2}{|c|}{ Intervention } & \multicolumn{2}{|c|}{ Control } & \multicolumn{2}{|c|}{ Intervention } \\
\hline & $r$ & $p$-value & $r$ & $p$-value & $r$ & $p$-value & $r$ & $p$-value & $r$ & $p$-value & $r$ & $p$-value & $r$ & $p$-value & $r$ & $p$-value & $r$ & $p$-value & $r$ & $p$-value \\
\hline Vigour & 0.36 & 0.09 & 0.22 & 0.21 & 0.26 & 0.25 & 0.27 & 12 & 0.06 & 0.81 & -0.12 & 0.47 & 0.12 & 0.47 & 0.01 & 0.96 & 0.24 & 0.29 & -0.12 & 0.5 \\
\hline Dedication & 0.34 & 0.12 & 0.30 & 0.09 & 0.34 & 0.12 & 0.13 & 0.48 & -0.12 & 0.60 & -0.13 & 0.48 & 0.13 & 0.48 & -0.01 & 0.94 & 0.02 & 0.92 & -0.04 & 0.85 \\
\hline Absorption & 0.18 & 0.43 & 0.31 & 0.08 & 0.14 & 0.53 & 0.17 & 0.33 & 0.04 & 0.87 & -0.26 & 0.15 & -0.02 & 0.15 & -0.08 & 0.64 & 0.11 & 0.62 & -0.12 & 0.52 \\
\hline
\end{tabular}

JDRS, Job Demands-Resources Scale; $r$, Pearson's r correlation coefficients.

$*, p<0.05 ; * *, p<0.01$.

Tims et al., 2013; Wrzesniewski \& Dutton, 2001). For instance, Mislim (2015) reported that employees of an international airport operator $(n=88)$ who reported a high level of jobcrafting behaviour had higher levels of work engagement. Furthermore, the present results are consistent with those from similarly designed job-crafting intervention studies (Van Mersbergen, 2012; Van Wingerden et al., 2017a). For instance, Van Mersbergen (2012) reported that, at a postintervention measurement, hospital nurses exposed to the intervention $(n=32)$ showed significant change from preintervention and scored higher than unexposed controls $(n=26)$ on UWES-derived measures of work engagement.

Hence, analyses of the UWES-17 data suggested that exposure to job-crafting intervention increased work engagement. Subsequent analyses of data from the other two questionnaires (the JCS and the JDRS), and of correlations amongst scores on the three questionnaires, attempted to answer the question of whether changes in job resources and job demands were major drivers of this increase in work engagement. Although no job-crafting intervention study has used the same JCS and JDRS measures as the present study, numerous longitudinal studies suggest, either directly or indirectly, that increased engagement in job-crafting activities can lead to positive changes in the balance of job demands and resources (e.g. Gordon et al., 2018; Petrou et al., 2012; Tims et al., 2013; Van Wingerden, Bakker, \& Derks, 2017b).

Analyses of the JCS data indicated a significant Time (preintervention, post-intervention) $\times$ Group (intervention, control) interaction effect on each of the JCS, namely, Increasing Social Job Resources, Increasing Structural Job Resources, Increasing
Challenging Job Demands and Decreasing Hindering Job Demands subscale scores. Post-intervention Increasing Social Job Resources and Increasing Structural Job Resources scores for participants in the Intervention group were, on average, significantly higher than those for participants in the Control group. Although post-intervention scores for the other two JCS subscales (Increasing Challenging Job Demands and Decreasing Hindering Job Demands) were much higher for participants in the Intervention group than for those in the Control group, the magnitude of average difference did not reach statistical significance. Again, this result is consistent with data presented by Van Mersbergen (2012), who showed, using a modified version of the JCS (Petrou et al., 2012), that nurses exposed to the intervention (but not those in the unexposed Control group) showed significant changes from pre- to post-intervention on variables, reflecting increased job resources and decreased job demands. However, in contrast to the results of the present study, Van Wingerden et al. (2017a) found that primary school teachers exposed to an intervention $(n=32)$ showed significantly increased post-intervention scores on the JCS Increasing Challenging Job Demands and Decreasing Hindering Job Demands subscales but not on the Increasing Social Job Resources and Increasing Structural Job Resources subscales.

One possible explanation for the contradictory findings across studies could relate to the context and setting of the research. As mentioned in the Introduction, the construction industry's deadline-driven nature may influence the ability to mitigate job demands. This could explain why respondents in the current study may have engaged more fervently in increasing social and structural resources to buffer the effects of job demands. Although not empirically tested, the 
researcher experienced improved communication as one of the key outcomes of the job-crafting intervention. Such improved communication can be seen as an interpersonallevel job resource (Schaufeli \& Bakker, 2004), where employees experience support from colleagues.

Analyses of the JDRS data detected a significant Time (preintervention, post-intervention) $\times$ Group (intervention, control) interaction effect on JDRS Growth Opportunities and Organisational Support (but not Advancement) scores. In each of the former two cases, scores for Intervention-group participants increased, whilst scores for Control-group participants decreased, from pre- to post-intervention. Within the Intervention group data, the analysis detected two positive associations: between JCS Increasing Social Job Resources and JDRS Growth Opportunities, and between JCS Increasing Challenging Job Demands and JDRS Organisational Support. Within the Control group data, however, the analysis detected no statistically significant positive correlations, thus confirming the a priori prediction. With regard to the job demand dimensions, analyses detected no significant main or interaction effects with regard to either JDRS Overload or Job Insecurity, and no significant between-group differences with regard to post-intervention JDRS Overload or Job Insecurity scores.

These results provide some evidence for the positive impact of aspects of a job-crafting intervention on changing the availability of job resources (as measured, specifically, by the JDRS Growth Opportunities and Organisational Support variables) and the presence of job demands to the employee. This result is consistent with several previous studies, suggesting that a key component of an employees' jobcrafting activity is finding ways to increase structural and social job resources and decrease hindering job demands (e.g. Rudolph, Katz, Lavigne, \& Zacher, 2017; Tims \& Bakker, 2010; Van den Heuvel, Demerouti, \& Peeters, 2015). In one of the more recent (cross-sectional) examples from the literature, Nell (2015) reported, based on survey data from 311 nurses employed within a private-sector hospital group, a statistically significant and positive relationship between involvement in job-crafting activities, as measured by the JCS, and job resources, as measured by the JDRS.

The results of the correlation analyses indicate that within the Intervention-group data, positive associations exist between scores on the UWES-17 Absorption subscale and those of three JCS subscales (Increasing Social Job Resources, Increasing Structural Job Resources and Increasing Challenging Job Demands), and between scores on the UWES-17 Vigour subscale and those on the JCS Increasing Challenging Job Demands subscale. Within the Control group data, the analysis detected two unpredicted positive associations (between JCS Increasing Structural Job Resources and UWES-17 Dedication and Absorption). The result for the Intervention group is consistent with several previous studies describing a strong positive relationship between increased employee involvement in job-crafting activities and improved work engagement (e.g. Bakker et al., 2012; Nell, 2015;
Tims et al., 2013; Wrzesniewski \& Dutton, 2001). In a metaanalysis of 122 independent studies ( $N=35670$ workers), Rudolph et al. (2017) found that proactive work behaviour, as encapsulated by job-crafting activities, bore a strong positive relationship to work engagement. Bakker (2011) heeded that the relationship between job crafting and work engagement is dynamic. Thus, employees who are engaged and experience positive affect are more likely to utilise personal agency to proactively change their jobs as they are better able to see the possibilities in their jobs (Bakker et al., 2012). This is in line with the JCS Increasing Structural Resources, which focusses on autonomy and seeking opportunities for development. This may possibly explain the unexpected significant relationships found in the Control group. However, further research that also takes contextual variables into account may be needed to effectively explain this finding.

Finally, the analyses disconfirmed a statistically significant positive correlation between pre- to post-intervention changes in the JDRS indices of growth opportunities, organisational support and advancement and pre- to postintervention changes in the UWES-17 indices (Vigour, Dedication and Absorption) for the Intervention group. Furthermore, no statistically significant negative correlation between pre- to post-intervention changes in the JDRS indices of overload and job insecurity and pre- to post-intervention changes in the UWES-17 indices (Vigour, Dedication and Absorption) was found. Although a sizable literature on JD-R theory (e.g. Mäkikangas, Bakker, \& Schaufeli, 2017; Van Wingerden et al., 2017 a) suggests that changes in the balance of job demands and resources should have an impact on work engagement, this is not the first study to report data featuring mixed evidence regarding the relationship between the two. For instance, Fruwert (2014) reported that, after a 1-week job-crafting intervention, both personal and social resources increased in her sample $(N=214$, Dutch academic researchers) but that these increases were accompanied by an increase in negative feelings about work (e.g. heightened psychological distress) and by no significant increase in work engagement, as measured by a short form of the UWES (Schaufeli, Bakker, \& Salanova 2006).

One way to account for these negative results might be to examine ways in which specific characteristics of particular jobs (e.g. those in academia versus those in a private-sector hospital) might affect the predictions made by JD-R theory. A complementary account might centre on the fact that the effects of job demands and resources on work engagement might require time to develop, particularly because within certain employment situations, work engagement is fairly stable and difficult to shift using a brief intervention (Victor \& Hoole, 2017; Xanthopoulou, Bakker, Demerouti, \& Schaufeli, 2009). Furthermore, some work environments might feature structural job demands (e.g. long working hours) that may simultaneously be: (1) outside of the authoritative scope of the employee (and therefore be immune to any form of traditional job-crafting intervention) and (2) closely associated with levels of work engagement. 


\section{Limitations and recommendations}

A first limitation concerns the size and nature of the sample and whether those allow generalisation of the findings. Regarding the sample size, although it was sufficient to provide adequate power for the inferential analyses, a larger sample would allow a stronger platform upon which to build a solid base of conclusions. Regarding the nature of the sample, all participants were employees of a single construction company. Although, on the face of it, this fact limits the generalisability of the findings, there is no $a$ priori reason to suggest that the context of this particular company is so different to that of other construction enterprises that these results cannot be informative for them.

A second limitation concerns the method of data collection. All data were collected via self-report questionnaires that are prone to social desirability influences and to experimenter demand effects (Rosenthal \& Rosnow, 2007). Future research of this kind should therefore include, as outcomes, behavioural observations (e.g. manager ratings of employee performance, over both the short and the long term) as well as subjective evaluations of employee success in the work role post-intervention.

A third limitation concerns the fact that participation in the study was voluntary and that, therefore, the study's findings might have been biased in particular ways. Previous research suggests that voluntary employee participation in surveys may be an outcome of employee engagement (De la Rocha, 2015). Thus, those employees who volunteered to participate may already have been experiencing high rates of engagement, and might therefore have been willing to perform extra-role tasks.

With regard to recommendations to improve job-crafting interventions, one might consider employing team job crafting alongside individual job crafting. A team-level intervention (as described, for instance, by McClelland, Leach, Clegg, \& McGowan, 2014) might allow a focus on changing structural job demands (e.g. working hours), and on modifying team tasks so that each team member's role can change in concert with that of his or her colleagues. Secondly, and from a more practical perspective, any job-crafting intervention should probably be run off-site, and at a time when employees do not have urgent competing demands (e.g. when they are close to completing a job and the work only requires minor finishes). Thirdly, any evaluation of this tailored intervention should include a wider range of outcome measures than the sole work engagement measure used here. Previously published jobcrafting intervention studies (e.g. Van den Heuvel et al., 2015; Van Mersbergen, 2012; Van Wingerden et al., 2017b) have included measures of, for instance, job-related affective wellbeing, psychological distress, self- and other-rated work performance, self-efficacy and burnout.

\section{Conclusion}

Overall, the current findings sit comfortably and consistently alongside a relatively rich literature, which suggests that employees who take a proactive role in crafting their jobrelated tasks and environments will be more engaged in their work (e.g. Nell, 2015; Petrou et al., 2012; Tims et al., 2013). More specifically, the present study adds to a growing body of literature, indicating that even brief job-crafting interventions can have positive effects on the number of jobcrafting behaviours in which employees engage, and on separate dimensions of work engagement (Van Mersbergen, 2012; Van Wingerden et al., 2017a) (but see Van den Heuvel et al., 2015).

The current findings did not, however, confirm the a priori conjecture that the relationship between changes in jobcrafting behaviours and changes in work engagement is mediated by changes in the balance of job demands to job resources. Although such a mediating relationship is based on principles derived from JD-R theory (Bakker \& Demerouti, 2007, 2014; Demerouti, Bakker, Nachreiner, \& Schaufeli, 2001), and although numerous empirical studies have confirmed many of the tenets of that theory (e.g. Bakker \& Demerouti, 2017; Van den Heuvel et al., 2015; Van Wingerden, Bakker, \& Derks, 2016), the current analyses (1) only partially confirmed that changes in job-crafting behaviours were associated with changes in job demands and resources and (2) detected no significant relationship between changes in job demands and resources and changes in work engagement. In summary, then, one might suggest that participants in the Intervention group benefitted in that they began crafting their jobs more proactively and in that they became more engaged in their work, but one must stop short of attributing those improvements to increasing social or structural job resources, or to decreasing hindering job demands or increasing challenging job demands.

Although further research is needed to describe the exact mechanisms by which job-crafting interventions work, the kind of intervention used here seems to have the potential to enable employees to proactively build a motivating work environment and to improve their own job satisfaction.

\section{Acknowledgements}

The research organisation is acknowledged for providing access to participants.

\section{Competing interests}

The authors declare that they have no financial or personal relationships that may have inappropriately influenced them in writing this article

\section{Authors' contributions}

This article is an outflow of the MCom mini-thesis by E.C.T. who conceptualised the study, hosted the job-crafting intervention and collected all the data. M.d.P. was the supervisor of the study, and K.G.F.T. assisted with the statistical analysis. E.C.T., M.d.P. and K.G.F.T. worked collaboratively on the draft article. 


\section{Funding information}

This research received no specific grant from any funding agency in the public, commercial or not-for-profit sectors.

\section{Data availability statement}

Data can be requested from the corresponding author.

\section{Disclaimer}

All the views and opinions expressed in this article are that of the authors and not an official position of the institution or the funder.

\section{References}

Albdour, A.A., \& Altarawneh, I.I. (2014). Employee engagement and organizational commitment: Evidence from Jordan. International Journal of Business, 19(2), 192-212.

Bakker, A.B. (2011). An evidence-based model of work engagement. Current Directions in Psychological Science, 20(4), 265-269. https://doi.org/10.1177/0963721411414534

Bakker, A.B. (2014). Daily fluctuations in work engagement: An overview and current directions. European Psychologist, 19(4), 227-236. https://doi.org/10.1027/10169040/a000160

Bakker, A.B., \& Demerouti, E. (2007). The job demands-resources model: State of the art. Journal of Managerial Psychology, 22(3), 309-328. https://doi.org/10.1108/ 02683940710733115

Bakker, A.B., \& Demerouti, E. (2014). Job demands-resources theory. In P.Y. Chen \& C.L. Cooper (Eds.), Wellbeing: A complete reference guide (Vol. III, pp. 37-64). Hoboken, NJ: Wiley-Blackwell.

Bakker, A.B., \& Demerouti, E. (2017). Job demands-resources theory: Taking stock and looking forward. Journal of Occupational Health Psychology, 22(3), 273-285. https://doi.org/10.1037/ocp000005

Bakker, A.B., \& Leiter, M.P. (2010). Work engagement: A handbook of essential theory and research. New York, NY: Psychology Press.

Bakker, A.B., Oerlemans, W.G., \& Ten Brummelhuis, L.L. (2013). Becoming fully engaged in the workplace: What individuals and organizations can do to foster work engagement. In R.J. Burke \& C.L. Cooper (Eds.), The fulfilling workplace: The organization's role in achieving individual and organizational health (pp. 55-70). New York, NY: Routledge.

Bakker, A.B., Tims, M., \& Derks, D. (2012). Proactive personality and job performance: The role of job crafting and work engagement. Human relations, 65(10) The role of job crafting and work engagement. Humar
1359-1378. https://doi.org/10.1177/0018726712453471

Barkhuizen, N., \& Rothmann, S. (2006). Work engagement of academic staff in South African higher education institutions. Management Dynamics: Journal of the Southern African Institute for Management Scientists, 15, 38-46.

Bell, N., Powell, C., \& Sykes, P. (2015). Securing the well-being and engagement of construction workers: An initial appraisal of the evidence. Paper presented at the 31st Annual Association of Researchers in Construction Management (ARCOM) Conference, 7-9 September 2015, Lincoln.

Berg, J.M., Dutton, J.E., \& Wrzesniewski, A. (2013). Job crafting and meaningful work. In B.J. Dik, Z.S. Byrne, \& M.F. Steger (Eds.), Purpose and meaning in the workplace (pp. 81-104). Washington, DC: American Psychological Association.

Bhatnagar, J. (2007). Talent management strategy of employee engagement in Indian ITES employees: Key to retention. Employee Relations, 29(6), 640-663. https:// doi.org/10.1108/01425450710826122

Bowen, P., Edwards, P., Lingard, H., \& Cattell, K. (2014). Occupational stress and job demand, control and support factors among construction project consultants. International Journal of Project Management, 32(7), 1273-1284. https://doi. org/10.1016/j.ijproman.2014.01.008

Brenninkmeijer, V., \& Hekkert-Koning, M. (2015). To craft or not to craft: The relationships between regulatory focus, job crafting and work outcomes. Career Development International, 20(2), 147-162. https://doi.org/10.1108/CDI-12-2014-0162

Coetzee, S.E., \& Rothmann, S. (2005). Work engagement of employees at a higher education institution in South Africa. Southern African Business Review, 9, 23-34.

Crawford, E.R., Lepine, J.A., \& Rich, B.L. (2010). Linking job demands and resources to employee engagement and burnout: A theoretical extension and meta-analytic test. Journal of Applied Psychology, 95(5), 834-848. https://doi.org/10.1037/ a0019364

De Braine, R., \& Roodt, G. (2011). The Job Demands-Resources model as predictor of work identity and work engagement: A comparative analysis. SA Journal of Industrial Psychology, 37(2), 52-62. https://doi.org/10.4102/sajip.v37i2.889

De la Rocha, A.M. (2015). The relationship between employee engagement and survey response rate with union membership as a moderator. Master's thesis. San Jose State University, San Jose, CA.

De Villiers, J. (Producer). (2017, March 2, 2017). Structural collapse at Charlotte Maxeke hospital. Retrieved from http://www.news24.com/SouthAfrica/News/ breaking-structural-collapse-at-charlotte-maxeke-hospital-20170302
Demerouti, E. (2014). Design your own job through job crafting. European Psychologist, 19, 237-247. https://doi.org/10.1027/1016-9040/a000188

Demerouti, E., Bakker, A.B., Nachreiner, F., \& Schaufeli, W.B. (2001). The job demandsresources model of burnout. Journal of Applied Psychology, 86(3), 499-512. https://doi.org/10.1037/0021-9010.86.3.499

Evans, J. (Producer). (2016, May 24). Tongaat Mall collapse report to be given to NPA. Retrieved from http://www.news24.com/SouthAfrica/News/tongaat-mallcollapse-report-to-be-given-to-npa-20160524

Field, L.K., \& Buitendach, J.H. (2011). Happiness, work engagement and organisationa commitment of support staff at a tertiary education institution in South Africa. SA Journal of Industrial Psychology, 37(1), 1-10. https://doi.org/10.4102/sajip. v37i1.946

Fruwert, R.M. (2014). How can researchers cope with the academic competition? Testing a job crafting intervention. Master's thesis. University of Amsterdam, Amsterdam.

Gordon, H.J., Demerouti, E., Le Blanc, P.M., Bakker, A.B., Bipp, T., \& Verhagen, M.A.M.T. (2018). Individual job redesign: Job crafting interventions in healthcare. Journal of Vocational Behavior, 104, 98-114. https://doi.org/10.1016/j.jvb.2017.07.002

Grant, A.M., \& Ashford, S.J. (2008). The dynamics of proactivity at work. Research in Organizational Behavior, 28, 3-34. https://doi.org/10.1016/j.riob.2008.04.002

Grant, A.M., \& Parker, S.K. (2009). Redesigning work design theories: The rise of relational and proactive perspectives. Academy of Management Annals, 3, 317-375.

Lee, S.-H., Shin, Y., \& Baek, S.I. (2017). The impact of job demands and resources on job crafting. Journal of Applied Business Research, 33(4), 829-842. https://doi. org/10.19030/jabr.v33i4.10003

Lyons, P. (2008). The crafting of jobs and individual differences. Journal of Business and Psychology, 23(1-2), 25-36. https://doi.org/10.1007/s10869-008-9080-2

Mäkikangas, A., Bakker, A.B., \& Schaufeli, W.B. (2017). Antecedents of daily team job crafting. European Journal of Work and Organizational Psychology, 26(3), 421433. https://doi.org/10.1080/1359432X.2017.1289920

Maslach, C., Schaufeli, W.B., \& Leiter, M.P. (2001). Job burnout. Annual Review of Psychology, 52, 397-422.

McClelland, G.P., Leach, D.J., Clegg, C.W., \& McGowan, I. (2014). Collaborative crafting in call centre teams. Journal of Occupational and Organizational Psychology, 87(3), 464-486. https://doi.org/10.1111/joop.12058

Mislim, R. (2015). Job crafting in organizations: A valuable approach for job performance or just a theoretical framework? Master's thesis. Radboud University, Nijmegen.

Mudrak, J., Zabrodska, K., Kveton, P., Jelinek, M., Blatny, M., Solcova, I., \& Machovcova, K. (2018). Occupational well-being among university faculty: A job demands-resources model. Research in Higher Education, 59, 325-348. https://doi.org/10.1007/s11162-017-9467-x

Nell, E. (2015). Testing the job demands-resources model on nurses. Master's thesis. Stellenbosch University, Stellenbosch.

Ogungbamila, B. (2018). Positive employee behaviors and occupational burnout in healthcare workers: Moderating roles of work engagement. Indian Journal of Positive Psychology, 9(3), 404-412.

Olusa, A.O., \& Afolabi, O.A. (2017). Job demand and job involvement among employees in construction and manufacturing industries: Mediating role of occupational burnout. International Journal of Applied Psychology, 7(1), 19-28. https://doi.org/10.5923/j.ijap.20170701.03

Peral, S., \& Geldenhuys, M. (2016). The effects of job crafting on subjective well-being amongst South African high school teachers. SA Journal of Industrial Psychology, 42(1), 1-13. https://doi.org/10.4102/sajip.v42i1.1378

Petrou, P., Demerouti, E., Peeters, M.C.W., Schaufeli, W.B., \& Hetland, J. (2012). Crafting a job on a daily basis: Contextual correlates and the link to work engagement. Journal of Organizational Behavior, 33(3), 1120-1141. https://doi. org/10.1002/job.1783

Potter, D. (Producer). (2016, December 22). Five South African structural collapses in 2016. Retrieved from https://citizen.co.za/news/news-cns/1381833/five-southafrican-structural-collapses-2016/

Rosenthal, R., \& Rosnow, R.L. (2007). Essentials of behavioral research: Methods and data analysis (3rd edn.). Boston, MA: McGraw-Hill.

Rothmann, S. (2003). Burnout and engagement: A South African perspective. SA Journal of Industrial Psychology, 29(4), 16-25. https://doi.org/10.4102/sajip. v29i4.121

Rothmann, S., Mostert, K., \& Strydom, M. (2006). A psychometric evaluation of the Job Demands-Resources Scale in South Africa. SA Journal of Industrial Psychology, 32(4), 76-86. https://doi.org/10.4102/sajip.v32i4.239

Rudolph, C.W., Katz, I.M., Lavigne, K.N., \& Zacher, H. (2017). Job crafting: A metaanalysis of relationships with individual differences, job characteristics, and work outcomes. Journal of Vocational Behavior, 102, 112-138. https://doi. org/10.1016/j.jvb.2017.05.008

Sakuraya, A., Shimazu, A., Eguchi, H., Kamiyama, K., Hara, Y., Namba, K., \& Kawakami, N. (2017). Job crafting, work engagement, and psychological distress among Japanese employees: A cross-sectional study. BioPsychoSocial Medicine, 11(6), 1-7. https://doi.org/10.1186/s13030-017-0091-y

Schaufeli, W.B., \& Bakker, A.B. (2004). Job demands, job resources, and their relationship with burnout and engagement: A multi-sample study. Journal of Organizational Behavior, 25(3), 293-315. https://doi.org/10.1002/job.248

Schaufeli, W.B., Bakker, A.B., \& Salanova, M. (2006). The measurement of work engagement with a short questionnaire: A cross-national study. Educational and Psychological Measurement, 66, 701-716. 
Steffens, N.K., Yang, J., Jetten, J., Haslam, S.A., \& Lipponen, J. (2018). The unfolding impact of leader identity entrepreneurship on burnout, work engagement, and turnover intentions. Journal of Occupational Health Psychology, 23(3), 373-387. turnover intentions. Journal of Occupat
https://doi.org/10.1037/ocp0000090

Tims, M., \& Bakker, A.B. (2010). Job crafting: Towards a new model of individual job redesign. SA Journal of Industrial Psychology, 36(2), 1-9. https://doi.org/10.4102/ sajip.v36i2.841

Tims, M., Bakker, A.B., \& Derks, D. (2012). Development and validation of the job crafting scale. Journal of Vocational Behavior, 80(1), 173-186. https://doi.org/10. 1016/j.jvb.2011.05.009

Tims, M., Bakker, A.B., \& Derks, D. (2013). The impact of job crafting on job demands, job resources, and well-being. Journal of Occupational Health Psychology, 18(2), 230-240. https://doi.org/10.1037/a0032141

Tims, M., Bakker, A.B., \& Derks, D. (2014). Daily job crafting and the self-efficacyperformance relationship. Journal of Managerial Psychology, 29(5), 490-507. https://doi.org/10.1108/JMP-05-2012-0148

Van den Heuvel, M., Demerouti, E., \& Peeters, M. (2012). Succesvol Job Craften door middel van een groepstraining. In J. De Jonge \& M.C.W. Peeters (Eds.), Scherp in werk: 5 routes naar optimale inzetbaarheid (pp. 27-49). Assen: Koninklijke Van Gorcum.

Van den Heuvel, M., Demerouti, E., \& Peeters, M.C.W. (2015). The job crafting intervention: Effects on job resources, self-efficacy, and affective well-being. Journal of Occupational and Organizational Psychology, 88, 511-532. https://doi. org/10.1111/joop.12128

Van Mersbergen, J. (2012). The test and evaluation of a job crafting intervention in healthcare. Master's thesis. Technical University Eindhoven. School of Industria Engineering, Eindhoven.
Van Wingerden, J., Bakker, A.B., \& Derks, D. (2016). A test of a job demandsresources intervention. Journal of Managerial Psychology, 31(3), 686-701. https://doi.org/10.1108/JMP-03-2014-0086

Van Wingerden, J., Bakker, A.B., \& Derks, D. (2017a). Fostering employee well-being via a job crafting intervention. Journal of Vocational Behavior, 100, 164-174. https://doi.org/10.1016/j.jvb.2017.03.008

Van Wingerden, J., Derks, D., \& Bakker, A.B. (2017b). The impact of personal resources and job crafting interventions on work engagement and performance. Human Resource Management, 56(1), 51-67. https://doi.org/10.1002/hrm.21758

Victor, J., \& Hoole, C. (2017). The influence of organisational rewards on workplace trust and work engagement. SA Journal of Human Resource Management, 15, a853. https://doi.org/10.4102/sajhrm.v15i0.853

Vignoli, M., Muschalla, B., \& Mariani, M.G. (2017). Workplace phobic anxiety as a mental health phenomenon in the job demands-resources model. BioMed Research International, 2017, 3285092, 10 pages. https://doi.org/10.1155 /2017/3285092

Whiteoak, J.W., \& Mohamed, S. (2016). Employee engagement, boredom and frontline construction workers feeling safe in their workplace. Accident Analysis \& Prevention, 93, 291-298. https://doi.org/10.1016/j.aap.2015.11.001

Wrzesniewski, A., \& Dutton, J.E. (2001). Crafting a job: Revisioning employees as active crafters of their work. Academy of Management Review, 26(2), 179-201. https://doi.org/10.5465/amr.2001.4378011

Xanthopoulou, D., Bakker, A.B., Demerouti, E., \& Schaufeli, W.B. (2009). Reciprocal relationships between job resources, personal resources, and work engagement. Journal of Vocational Behavior, 74(3), 235-244. https://doi.org/10.1016/j.jvb 2008.11.003 